\title{
Things We Do For No Reason: Contact Precautions for MRSA and VRE
}

\author{
Kristen Young, DO, MEd ${ }^{1,2 *}$, Sarah B Doernberg, MD, MAS ${ }^{3}$, Ruth Franks Snedecor, MD ${ }^{1,2}$, Emily Mallin, MD, SFHM ${ }^{1,2}$
}

\begin{abstract}
'Department of Medicine, University of Arizona College of Medicine, Phoenix, Arizona; ${ }^{2}$ Division of Hospital Medicine, Department of Internal Medicine, Banner - University Medical Center, Phoenix, Arizona; ${ }^{3}$ Division of Infectious Disease, Department of Medicine, University of California, San Francisco, California.
\end{abstract}

Inspired by the ABIM Foundation's Choosing Wisely® campaign, the "Things We Do for No Reason" (TWDFNR) series reviews practices that have become common parts of hospital care but may provide little value to our patients. Practices reviewed in the TWDFNR series do not represent "black and white" conclusions or clinical practice standards but are meant as a starting place for research and active discussions among hospitalists and patients. We invite you to be part of that discussion.

\section{CASE}

A 67-year-old man is admitted to a telemetry ward for an acute myocardial infarction and treated with percutaneous coronary intervention. He is currently on day three of antibiotics for a methicillin-resistant Staphylococcus aureus (MRSA) lower extremity soft tissue infection that is healing without a draining wound. He is placed on contact precautions based on institutional infection control guidelines. The hospitalist overhears members of the team commenting on having to don gowns to see this patient each day and wonders aloud whether care is impacted by the use of contact precautions.

\section{BACKGROUND}

Contact precautions (CP) for patients with methicillin-resistant Staphylococcus aureus (MRSA) and vancomycin-resistant Enterococcus (VRE) infections are common in several hospitals. $\mathrm{CP}$ pose a significant burden to health systems, with an estimated $20 \%-25 \%$ of hospitalized patients on CP for MRSA or VRE alone. ${ }^{1} \mathrm{CP}$ are becoming increasingly more prevalent with state laws and the Veterans Affairs (VA) hospital system requiring active surveillance cultures (ASC) and subsequent $\mathrm{CP}$ when ASC are positive. ${ }^{2}$

\section{WHY YOU MIGHT THINK CONTACT PRECAUTIONS ARE HELPFUL FOR MRSA AND VRE?}

Supporters highlight the utility of CP in preventing the spread of infection, controlling outbreaks, and protecting healthcare workers from certain transmissible diseases. The Centers for

*Corresponding Author: Kristen Young, DO, MEd; Telephone: 602-839-5822; E-mail: Kjyoung12@email.arizona.edu; Twitter: @KristenYoung

Published online first February 20, 2019

Received: July 5, 2018; Revised: October 23, 2018;

Accepted: November 8, 2018

๑ 2019 Society of Hospital Medicine DOI 10.12788/jhm.3126
Disease Control and Prevention (CDC) recommended CP after prior studies demonstrated their effectiveness during outbreaks of transmissible infections. ${ }^{3} \mathrm{CP}$ were included in bundles alongside interventions such as improving hand hygiene, chlorhexidine gluconate (CHG) bathing, and ASC with targeted or universal decolonization. ${ }^{2}$ The VA MRSA bundle, for example, demonstrated a reduction of healthcare-associated MRSA in the ICU by $62 \%$ after implementation. The Society for Healthcare Epidemiology of America Research Network (SHEA) and the Infectious Diseases Society of America (IDSA) recommend CP for MRSA-infected and colonized patients in acute care settings to control outbreaks. ${ }^{4,5}$ The CDC also has broad recommendations supporting $\mathrm{CP}$ for all patients infected and previously identified as being colonized with target multidrug-resistant organisms (MDROs) without identifying which are considered to be "targets."

\section{WHY CONTACT PRECAUTIONS MAY NOT BE HELPFUL FOR MRSA AND VRE}

Despite current guidelines, cluster-randomized trials have not shown a benefit of initiating CP over usual care for the prevention of acquiring MRSA or VRE in the hospital. One study demonstrated no change in MRSA and VRE acquisition with broad screening and subsequent CP. ${ }^{7}$ Another study evaluated a universal gown and glove policy in an ICU setting and found a reduction in MRSA acquisition, but no reduction in VRE acquisition. ${ }^{8} \mathrm{~A}$ third study investigated hand hygiene and daily CHG bathing and noted a reduction in MRSA transmission rates, where CP for screened colonized patients had no effect on transmission of MRSA or VRE.?

In addition, a prospective trial at a large academic center over two six-month intervals utilized universal gloving with emollient-impregnated gloves compared with $\mathrm{CP}$ and found no difference in MRDO acquisition. Universal gloving was associated with higher hand hygiene rates than $\mathrm{CP} .{ }^{10}$ Another more recent retrospective observational study compared universal contact precautions (UCP) in ICUs to a historical nineyear baseline and concurrently to other nonuniversal CP ICUs. There was no significant decrease in MRDOs during the UCP period compared with baseline or with non-UCP units. ${ }^{11}$

Further interest in and scrutiny of $\mathrm{CP}$ prompted a recently published meta-analysis of 14 studies in which CP were eliminated. The rates of transmission of MRSA, VRE, or other MDROs studied were not impacted by discontinuation..$^{12}$ One of the studies included two large academic medical centers and assessed the impact of discontinuing CP for endemic MRSA and 
VRE. The bundled intervention included the discontinuation of CP for all carriers of MRSA and VRE, except patients with draining wounds, maintaining high hand hygiene rates, and $\mathrm{CHG}$ baths for nearly all patients. There was no significant increase in transmission rates, and the intervention saved the health system an estimated \$643,776 and 45,277 hours per year in healthcare worker time previously spent on donning and doffing personal protective equipment. ${ }^{13}$ Another large academic hospital published a time series approach of seven interventions to reduce healthcare-associated infections and noted no increase in MRSA or VRE transmission when CP were discontinued when combined with other horizontal preventions. ${ }^{14}$ Results were found to be similar in a high-risk population of patients with hematologic malignancies and hematopoietic stem cell transplantation, where both surveillance and CP for VRE were discontinued and did not impact the rates of VRE bacteremia. ${ }^{15}$

\section{WHY CONTACT PRECAUTIONS MAY BE HARMFUL}

Multiple studies have examined the deleterious effects of $\mathrm{CP}$, including a comprehensive systematic literature review of various adverse outcomes linked with $\mathrm{CP} .{ }^{16} \mathrm{CP}$ decrease the amount of time that healthcare workers $(\mathrm{HCW})$ spend with patients, ${ }^{17}$ create delays at admission and discharge, ${ }^{18}$ increase symptoms of anxiety and depression in patients, ${ }^{19,20}$ and decrease patient satisfaction with care. ${ }^{21,22}$ In a study conducted at the Cleveland Clinic Hospital, physician communication, staff responsiveness, patients' perception of cleanliness, and their willingness to recommend the hospital on the Hospital Consumer Assessment of Healthcare Providers and Systems survey were lower in each category for patients on CP when compared with patients not on $\mathrm{CP} .22$ Patients who are on $\mathrm{CP}$ are six times more likely to experience an adverse event in the hospital, including falls and pressure ulcers. ${ }^{23}$ A recent study from a large academic medical center demonstrated that noninfectious adverse events were reduced by $72 \%$ after discontinuing CP for MRSA and VRE. These events included postoperative respiratory failure, hemorrhage or hematoma, thrombosis, wound dehiscence, pressure ulcers, and falls or trauma. ${ }^{24}$

The financial costs of unnecessary CP have also been studied. A recent retrospective study examining a large cohort of patients on CP for MRSA demonstrated that when compared with nonisolated patients, those on MRSA CP had a 30\% increase in length of stay and a $43 \%$ increase in costs of care. Patients isolated for MRSA were $4.4 \%$ more likely than nonisolated individuals to be readmitted within 30 days after discharge, unrelated to MRSA. ${ }^{25}$ These data contribute to the growing evidence that a conscientious, patient-centered approach to CP is preferred to overly broad policies that compromise patient safety.

\section{WHEN CONTACT PRECAUTIONS}

\section{SHOULD BE USED FOR MRSA AND VRE}

Contact precautions for MRSA and VRE should be used to interrupt transmission during uncontrolled outbreaks, and in patients with open wounds, uncontained secretions, or incontinent diarrhea.
In addition, there are other commonly encountered organisms for which CP should be continued. CP should be used for active Clostridium difficile infection to prevent transmission. Due to the paucity of data regarding prevention of novel and highly resistant organisms and the complexity in treating these MDROs, it is reasonable to initiate CP in these cases. ${ }^{26}$ Examples include active infection with multidrug resistance, including carbapenem-resistant Enterobacteriaceae, highly drug-resistant Pseudomonas aeruginosa, and other emerging MDROs such as vancomycin-resistant or -indeterminate S. aureus (VRSA or VISA) and Candida auris. ${ }^{27}$ Limiting CP to instances where there is clear evidence to support will ensure patient safety and limit the harms associated with CP.

\section{WHAT YOU SHOULD DO INSTEAD}

Horizontal prevention aims to reduce the burden of all microorganisms. This includes techniques such as hand hygiene, antimicrobial stewardship, CHG bathing, and environmental cleaning methods to decrease colonization of all MDROs in hospital rooms. Compared with vertical prevention strategies that use active surveillance testing for colonization and $\mathrm{CP}$, horizontal interventions are the most effective means to reduce transmission of MDROs. ${ }^{28}$ The simplest and the most well-studied method for reducing transmission of all organisms in the hospital remains hand hygiene. ${ }^{29}$ High institutional hand hygiene rates of at least $90 \%$ are critical to the success of any initiative that seeks to eliminate CP.

CHG bathing has also been studied across multiple patient settings for reducing MRSA and VRE acquisition, catheter-associated urinary tract infections, and central line-associated bacterial infections. ${ }^{30}$ In addition, hospital-wide daily $\mathrm{CHG}$ bathing has been associated with decreased $C$. difficile infection, and the baths were well tolerated by patients. ${ }^{31}$

SHEA recently released recommendations for timing of discontinuation of CP for patients with MDROs and emphasized that hospital systems must take an individual approach to discontinuing $\mathrm{CP}$ that takes into account local prevalence, risk, and resources. ${ }^{32}$ The decision to not place a patient on $\mathrm{CP}$ is one side of this high-value coin. The other side is knowing when it is appropriate to discontinue CP.

\section{RECOMMENDATION}

- Discontinue the use of CP for MRSA and VRE in hospitals with low endemic rates and high hand hygiene compliance.

- Improve horizontal preventions by promoting hand hygiene, antimicrobial stewardship, and considering CHG bathing for all patients.

- Create a systematic approach to discontinuing CP and compare transmission of MRSA and VRE rates through microbiology surveillance before and after discontinuation.

\section{CONCLUSION}

Contact precautions for MRSA and VRE are another example of a "Thing We Do for No Reason". For most patients with MRSA and VRE, CP have not been shown to effectively reduce transmission. In addition, CP are expensive and associated 
with increased rates of patient adverse events. Hospitalists can lead the effort to ensure optimal hand hygiene and work with local infection control teams to reevaluate the utility of CP for patients with MRSA and VRE.

Do you think this is a low-value practice? Is this truly a "Thing We Do for No Reason?" Share what you do in your practice and join in the conversation online by retweeting it on Twitter (\#TWDFNR) and liking it on Facebook. We invite you to propose ideas for other "Things We Do for No Reason" topics by emailing TWDFNR@hospitalmedicine.org.

Disclosures: There are no conflicts of interest for any authors, financial or other.

\section{References}

1. Morgan DJ, Murthy R, Munoz-Price LS, et al. Reconsidering contact precautions for endemic methicillin-resistant Staphylococcus aureus and vancomycin-resistant Enterococcus. Infect Control Hosp Epidemiol. 2015;36(10):11631172. doi: 10.1017/ice.2015.156.

2. Jain $R$, Kralovic SM, Evans ME, et al. Veterans Affairs initiative to prevent methicillin-resistant Staphylococcus aureus infections. N Engl J Med. 2011;364(15):1419-1430. doi: 10.1056/NEJMoa1007474.

3. Siegel JD, Rhinehart E, Jackson M, Chiarello L. 2007 Guideline for isolation precautions: preventing transmission of infectious agents in health care settings. Am J Infect Control. 2007;35(10):S65-S164. doi: 10.1016/j.ajic.2007.10.007.

4. Calfee DP, Salgado CD, Milstone AM, et al. Strategies to prevent methicillin-resistant Staphylococcus aureus transmission and infection in acute care hospitals: 2014 Update. Infect Control Hosp Epidemiol. 2014;35(7):772-796. doi: $10.1086 / 676534$.

5. Mcdonald LC, Gerding DN, Johnson S, et al. Clinical practice guidelines for Clostridium difficile infection in adults and children: 2017 Update by the Infectious Diseases Society of America (IDSA) and Society for Healthcare Epidemiology of America (SHEA). Clin Infect Dis. 2018;66(7):987-994. doi: 10.1093/cid/ciy149.

6. Siegel JD, Rhinehart E, Jackson M, Chiarello L, Healthcare Infection Control Practices Advisory Committee. Management of multidrug-resistant organisms in healthcare settings, 2006. Am J Infect Control. 2007;35(10):S165-S193. doi: 10.1016/j.ajic.2007.10.006.

7. Huskins WC, Huckabee CM, O'Grady NP, et al. Intervention to reduce transmission of resistant bacteria in intensive care. N Engl J Med. 2011;364(15):1407-1418. doi: 10.1056/NEJMoa1000373.

8. Harris $A D$, Pineles $L$, Belton $B$, et al. Universal glove and gown use and acquisition of antibiotic-resistant bacteria in the ICU: a randomized trial. JAMA. 2013;310(15):1571-1580. doi: 10.1001/jama.2013.277815.

9. Derde LPG, Cooper BS, Goossens H, et al. Interventions to reduce colonisation and transmission of antimicrobial-resistant bacteria in intensive care units: an interrupted time series study and cluster randomized trial. Lancet Infect Dis. 2014;14(1):31-39. doi: 10.1016/S1473-3099(13)70295-0.

10. Bearman G, Rosato AE, Duane TM, et al. Trial of universal gloving with emollient-impregnated gloves to promote skin health and prevent the transmission of multidrug-resistant organisms in a surgical intensive care unit. Infect Control Hosp Epidemiol. 2010;31(5):491-497. doi: 10.1086/651671.

11. Furuya EY, Cohen B, Jia H, Larson EL. Long-term impact of universal contact precautions on rates of multidrug-resistant organisms in ICUs: a comparative effectiveness study. Infect Control Hosp Epidemiol. 2018;39(5):534-540. doi: 10.1017/ice.2018.35.

12. Marra AR, Edmond MB, Schweizer ML, Ryan GW, Diekema DJ. Discontinuing contact precautions for multidrug-resistant organisms: a systematic literature review and meta-analysis. Am J Infect Control. 2018;46(3):333-340. doi: 10.1016/j.ajic.2017.08.031

13. Martin EM, Russell D, Rubin Z, et al. Elimination of routine contact precautions for endemic methicillin-resistant Staphylococcus aureus and vancomycin-resistant Enterococcus: A retrospective quasi-experimental study. Infect Control Hosp Epidemiol. 2016;37(11):1323-1330. doi: 10.1017/ice.2016.156.

14. Bearman G, Abbas S, Masroor N, et al. Impact of discontinuing contact precautions for methicillin-resistant Staphylococcus aureus and vancomycin-resistant Enterococcus: an interrupted time series analysis. Infect Control Hosp Epidemiol. 2018;39(6):676-682. doi: 10.1017/ice.2018.57.

15. Almyroudis NG, Osawa R, Samonis G, et al. Discontinuation of systematic surveillance and contact precautions for vancomycin-resistant Enterococcus (VRE) and its impact on the incidence of VRE faecium bacteremia in patients with hematologic malignancies. Infect Control Hosp Epidemiol. 2016;37(4):398-403. doi: 10.1017/ice.2015.310.

16. Morgan DJ, Diekema DJ, Sepkowitz K, Perencevich EN. Adverse outcomes associated with contact precautions: a review of the literature. Am J Infect Control. 2009;37(2):85-93. doi: 10.1016/j.ajic.2008.04.257.

17. Saint S, Higgins LA, Nallamothu BK, Chenoweth C. Do physicians examine patients in contact isolation less frequently? A brief report. Am J Infect Control. 2003;31(6):354-356. doi: 10.1016/S0196-6553(02)48250-8.

18. Goldszer RC, Shadick N, Bardon CG, et al. A program to remove patients from unnecessary contact precautions. J Clin Outcomes Manag. 2002;9(10):553-556.

19. Guilley-Lerondeau B, Bourigault C, Buttes A-CGD, Birgand G, Lepelletier D. Adverse effects of isolation: a prospective matched cohort study including 90 direct interviews of hospitalized patients in a French University Hospital. Eur J Clin Microbiol Infect Dis. 2016;36(1):75-80. doi: 10.1007/s10096-016-2772-z.

20. Kirkland KB, Weinstein JM. Adverse effects of contact isolation. Lancet. 1999;354(9185):1177-1178. doi: 10.1016/S0140-6736(99)04196-3.

21. Stelfox HT, Bates DW, Redelmeier DA. Safety of patients isolated for infection control. JAMA. 2003;290(14):1899-1905. doi: 10.1001/jama.290.14.1899.

22. Vinski J, Bertin M, Sun Z, et al. Impact of isolation on hospital consumer assessment of healthcare providers and systems scores: is isolation isolating? Infect Control Hosp Epidemiol. 2012;33(5):513-516. doi: 10.1086/665314.

23. Karki S, Leder K, Cheng AC. Patients under contact precautions have an increased risk of injuries and medication errors a retrospective cohort study. Infect Control Hosp Epidemiol. 2013;34(10):1118-1120. doi: 10.1086/673153.

24. Martin EM, Bryant B, Grogan TR, et al. Noninfectious hospital adverse events decline after elimination of contact precautions for MRSA and VRE. Infect Control Hosp Epidemiol. 2018;39(7):788-796. doi: 10.1017/ice.2018.93.

25. Tran K, Bell C, Stall N, et al. The effect of hospital isolation precautions on patient outcomes and cost of care: A multi-site, retrospective, propensity scorematched cohort study. J Gen Intern Med. 2017;32(3):262-268. doi: 10.1007/ s11606-016-3862-4.

26. Izadpanah M, Khalili H. Antibiotic regimens for treatment of infections due to multidrug-resistant Gram-negative pathogens: an evidence-based literature review. J Res Pharm Pract. 2015;4(3):105-114. doi: 10.4103/2279-042X.162360.

27. Savard P, Perl TM. Combating the spread of carbapenemases in Enterobacteriaceae: a battle that infection prevention should not lose. Clin Microbiol Infect. 2014;20(9):854-861. doi: 10.1111/1469-0691.12748.

28. Wenzel RP, Edmond MB. Infection control: the case for horizontal rather than vertical interventional programs. Int J Infect Dis. 2010;14(4):S3-S5. doi: 10.1016/j.jijid.2010.05.002.

29. Pittet D, Allegranzi B, Sax H, et al. Evidence-based model for hand transmission during patient care and the role of improved practices. Lancet Infect Dis. 2006;6(10):641-652. doi: 10.1016/S1473-3099(06)70600-4.

30. Climo MW, Yokoe DS, Warren DK et al. Effect of daily chlorhexidine bathing on hospital-acquired infection. N Engl J Med. 2013;368(6):533-542. doi: 10.1056/NEJMoa1113849.

31. Rupp ME, Cavalieri RJ, Lyden E, et al. Effect of hospital-wide chlorhexidine patient bathing on healthcare-associated infections. Infect Control Hosp Epidemiol. 2012;33(11):1094-1100. doi: 10.1086/668024.

32. Banach DB, Bearman G, Barnden $M$, et al. Duration of contact precautions for acute-care settings. Infect Control Hosp Epidemiol. 2018;39(2):127-144. doi: 10.1017/ice.2017.245. 